\title{
Empirical Study on the impact of Urbanization on air transport industry in Shanghai
}

\author{
Di Luan ${ }^{1,} a^{*}$ and Lu Qin ${ }^{2, b}$ \\ ${ }^{1}$ School of Traffic and Transportation, Beijing Jiaotong University, China \\ ${ }^{2}$ School of Traffic and Transportation, Beijing Jiaotong University, China

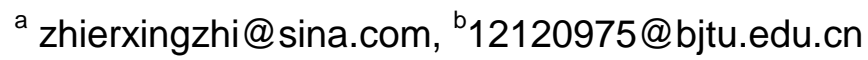

Keywords: Urbanization; Entropy; Impetus; Regression analysis; Factor analysis

\begin{abstract}
Urbanization is a process of overall development on the aspects of population, economy, society and land. As the carrier of economic, social communication and logistics interaction between the city and outside world, air transport industry is greatly affected by urbanization. By choosing 1995-2012's statistical data of population, economy, society and land to evaluate the overall level of urbanization and 1995-2012's statistical data of air cargo traffic and air passenger traffic to indicate the development of air transport industry, this paper establishes a comprehensive evaluation system of urbanization based on the method of entropy, and use correlation index and regression analysis model to analyzes the relation between urbanization and air transport industry development in Shanghai. The results show that urbanization has a strong correlation with air transport industry in Shanghai, and the urbanization of population, economy and land gradually become the main force to drive the development of air transport industry, among which the urbanization of economy is the most important force.
\end{abstract}

\section{Introduction}

Currently, many major cities in China, treasure the acceleration of urbanization and the development of air transport industry as the strategic measure, and build aviation metros or airport economic zones to motivate the interactive between urbanization and the air transport industry and thus upgrade the development of economy and society. During building or expanding airports, Beijing, Qingdao, Xiamen and other cities plan and build airport economic zone, in order to form the aviation city. However, the study by Yunchun Cao [4] found that airport is the basis for the emergence and development of the airport economy. It tells that only if reached a certain size, the air transport industry can generate effective interaction with urbanization and jointly promote the development of airport industry. And the new born air transport industry in most of cities has not reached a sufficient size yet, for which it's hard to meet the needs of metro aviation, and needs the support of urbanization. Therefore, how to play the leading role of urbanization on airport air transport industry, has become a key issue. From the dimensions of the power factor, this paper analyzes the relationship between the level of urbanization and the air transport industry in Shanghai during 1995-2012. It studies the impact of population urbanization, economic urbanization, land urbanization and social urbanization on air transport, so as to provide a scientific basis of development of the air transport industry.

\section{Comprehensive measurement of urbanization level in Shanghai}

Indicators and measurement methods. Taking into consideration the results of the academic research on integrated measurement methods on urbanization [1]-[3], this paper chooses four areas of urbanization, such as population urbanization, economy urbanization, land urbanization and social urbanization, with 16 indicators (Table 1), and establishes a comprehensive evaluation indicator system of urbanization. 
Table 1 Comprehensive evaluation indicator system on urbanization of Shanghai

\begin{tabular}{|c|c|}
\hline Type & indicator \\
\hline \multirow{4}{*}{$\begin{array}{l}\text { population } \\
\text { urbanization }\end{array}$} & Proportion of non-agricultural population in the total population \\
\hline & Non-agricultural population \\
\hline & Population employed in the Secondary and tertiary industries \\
\hline & Population density \\
\hline \multirow{4}{*}{$\begin{array}{l}\text { economy } \\
\text { urbanization }\end{array}$} & Real GDP per capita \\
\hline & Industrial output per capita \\
\hline & Proportion of tertiary industry output value in \\
\hline & Density of tertiary industry GDP \\
\hline \multirow{4}{*}{$\begin{array}{l}\text { land } \\
\text { urbanization }\end{array}$} & Built-up areas \\
\hline & The proportion of built-up areas \\
\hline & Area of public green space per capita \\
\hline & Area of paved road \\
\hline \multirow{4}{*}{$\begin{array}{l}\text { social } \\
\text { urbanization }\end{array}$} & Electricity consumption per capita \\
\hline & The number of college students per one thousand men \\
\hline & The number of hospital beds per one thousand men \\
\hline & Disposable income of urban households \\
\hline
\end{tabular}

This paper uses entropy method to determine the weight, to eliminate the impact of subjective factors. In information theory, entropy is the measure of the degree of uncertainty of system status. Generally speaking, the higher the entropy value, the smaller the difference, or the slower the change; conversely, the lower the entropy, the greater the difference, or sooner the change. Entropy has the higher credibility than subjective weighting method, suitable for multivariate index comprehensive evaluation. Evaluation procedure is as follows:

Establish original data matrix: Based on $m$ programs to be evaluated and $n$ terms of evaluation, form the original data matrix $X$ as follows. $x_{i j}$ is the index value of $\mathrm{j}$-th indicator in $\mathrm{i}$-th evaluation;

$$
X=\left\{\mathrm{x}_{i j}\right\}_{m \times n}(0 \leq i \leq m, 0 \leq j \leq n)
$$

Standardize original data: Definite the ideal evaluation value of $j$-th indicator is $x_{j}{ }^{*}$, whose number varies due to the nature of indicators. Definite $\mathrm{x}_{\mathrm{ij}}$ is the proximity that $\mathrm{x}_{\mathrm{ij}}$ is to $\mathrm{x}_{\mathrm{j}}{ }^{*}$. Forward indicators and negative indicators are as follows:

$$
\begin{aligned}
& x_{i j}^{\prime}=x_{i j} / x_{j}{ }^{*}{ }_{\text {max }} \\
& x_{i j}^{\prime}=x_{i j} / x_{j}{ }^{*}{ }_{\text {min }}
\end{aligned}
$$

Calculate standardized value matrix of index: Definite standardized value matrix is,

$$
Y=\left\{y_{i j}\right\}_{m \times n}, y_{i j}=x_{i j}^{\prime} / \sum x_{i j}^{\prime} 0 \leq y_{i j} \leq m
$$

Calculate the entropy of indicators:

$$
e_{j}=\left(-\frac{1}{\ln m}\right) \sum y_{i j} * \ln y_{i j}
$$

Calculate entropy redundancy:

$$
g_{j}=1-e_{j}
$$

Calculate the weight of index:

$$
w_{j}=g_{j} / \sum g_{j}
$$

Calculate the evaluation value of single indicator: Definite the product of weight value of $j$-th indicator and the proximity of the index value of $j$-th indicator in $i$-th evaluation in standardized value matrix, as the evaluation value of $\mathrm{x}_{\mathrm{ij}}$, represented by $\mathrm{f}_{\mathrm{ij}}$,

$$
f_{i j}=w_{j} * x_{i j}^{\prime}
$$

Calculate the evaluation value in i-th year: 


$$
f_{j}=\sum f_{i j}
$$

Measurement and analysis of the urbanization level in Shanghai. The data of built-up areas and area of public green space per capita are obtained from "China Urban Construction Statistical Yearbook" in 1995-2012. And others are obtained from "Shanghai Statistical Yearbook" in 1995-2012.

According to the step of entropy method, first of all, standardize the index of the original data in 1995-2012 in Shanghai. Due to the fact that indicators selected are ideal targets of the development of urbanization, use regularization formula. Secondly, based on the standardized data and the formula of entropy method, calculate the weight of each indicator (Table 2), and finally draw the evaluation value of urbanization comprehensive level and that of each subsystem in 1995-2012 in Shanghai.

Table 2 Weight of evaluation of subsystem on urbanization of Shanghai

\begin{tabular}{|c|c|c|c|c|}
\hline subsystem & $\begin{array}{c}\text { population } \\
\text { urbanization }\end{array}$ & $\begin{array}{c}\text { economy } \\
\text { urbanization }\end{array}$ & $\begin{array}{c}\text { land } \\
\text { urbanization }\end{array}$ & $\begin{array}{c}\text { social } \\
\text { urbanization }\end{array}$ \\
\hline weight & 0.26 & 0.2482 & 0.2373 & 0.2545 \\
\hline
\end{tabular}

It shows in the table 2 that weights of population urbanization and social urbanization are above 0.25 , while the weight of economy urbanization slightly below 0.25 and the weight of land urbanization significantly below 0.25 . These indicate that during 1995-2012, the focuses of urban Construction in Shanghai undergoes transferring gradually from economy and infrastructure to the demographic and social urbanization.

Table 3 Evaluation value of comprehensive urbanization level of Shanghai in1995-2012

\begin{tabular}{|c|c|c|c|c|c|c|c|c|c|}
\hline year & 1995 & 1996 & 1997 & 1998 & 1999 & 2000 & 2001 & 2002 & 2003 \\
\hline $\begin{array}{c}\text { comprehensive } \\
\text { evaluation value }\end{array}$ & 0.0414 & 0.0702 & 0.0946 & 0.1425 & 0.1739 & 0.2233 & 0.2696 & 0.3368 & 0.3962 \\
\hline $\begin{array}{c}\text { year } \\
\text { comprehensive } \\
\text { evaluation value }\end{array}$ & 0.5355 & 0.6129 & 0.6767 & 0.7267 & 0.7859 & 0.8233 & 0.8744 & 0.9187 & 0.9443 \\
\hline
\end{tabular}

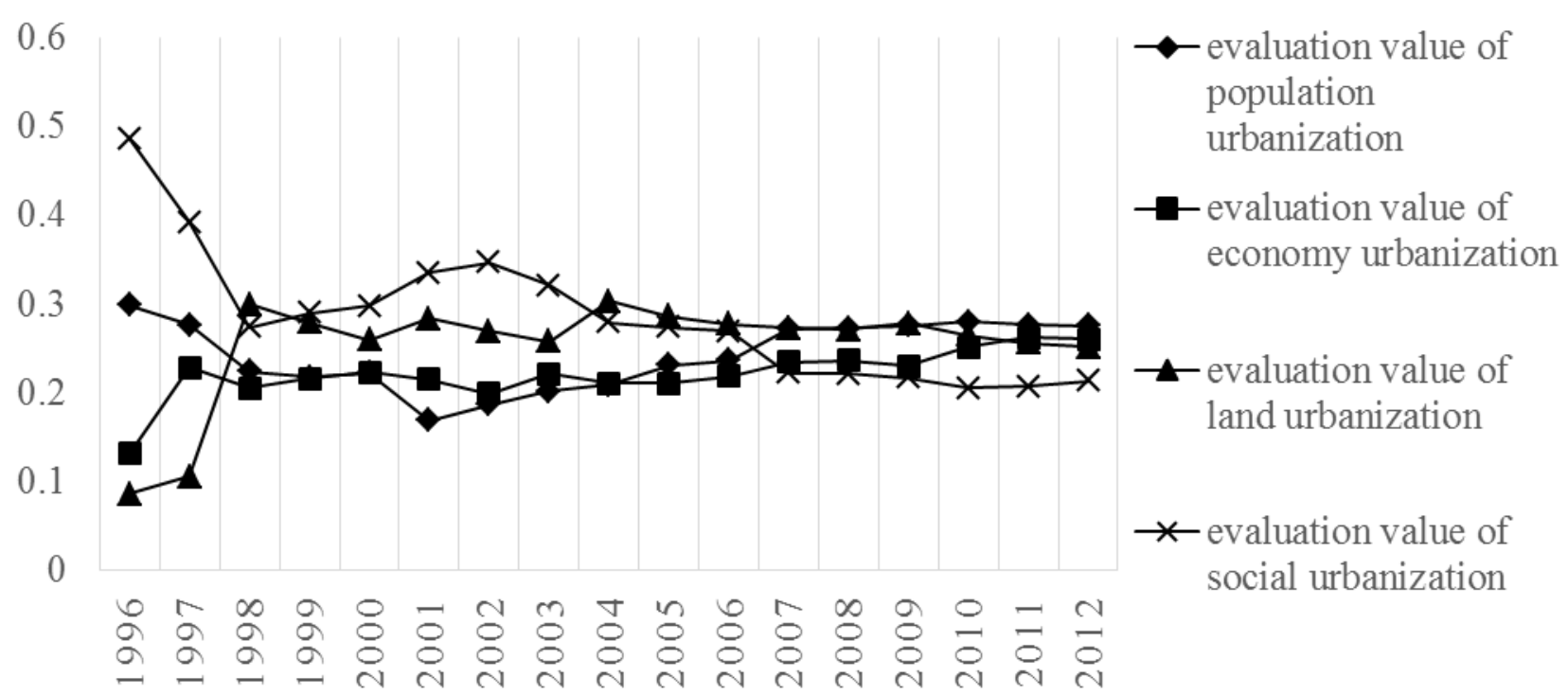

Fig. 1 Proportion of evaluation value of subsystem on urbanization of Shanghai in 1995-2012

It tells that in Fig. 1 and Table 3, the urbanization level of Shanghai is increasing steadily. During1995-2004, proportions of evaluation value of each subsystem on urbanization were changing dynamically and drastically when the urbanization of Shanghai was in the structure-adjustment period; During1995-2004, proportions of evaluation value of each subsystem on urbanization were holding 
steady at around 0.25 when the urbanization of Shanghai was in the coordination-development period.

\section{Analysis on the relationship between urbanization and the development of the air transport industry in Shanghai}

In 1995-2012, the Pearson correlation coefficient between evaluation value of urbanization level of Shanghai and air passenger throughput is 0.969 , while that between evaluation value of urbanization level of Shanghai and air cargo throughput is 0.990. It indicates that there is a significant correlation between the level of urbanization level and the level of the air transport industry in Shanghai.

The impact of urbanization on the air transport industry is reflected by the impact of population urbanization, economy urbanization, land urbanization and social urbanization on the air transport industry. Choose evaluation value of urbanization level (X) reflecting the urbanization level of Shanghai in1996-2012 and evaluation value of population urbanization $\left(\mathrm{X}_{1}\right)$, economy urbanization $\left(\mathrm{X}_{2}\right)$, land urbanization $\left(\mathrm{X}_{3}\right)$ and social urbanization $\left(\mathrm{X}_{4}\right)$, reflecting the level of urbanization subsystems, and choose the sum $\left(\mathrm{Y}_{1}\right)$ of the air passenger throughput of Hongqiao International Airport and Pudong International Airport and the sum $\left(\mathrm{Y}_{2}\right)$ of the air cargo throughput, as dependent variables. And then, establish the predicting model of multiple analyses on air throughput and evaluation value of urbanization subsystems, dealt separately in two periods, 1996-2004 and 2005-2012. Use factor analysis to eliminate the impact of multiple co-linear and achieve regression analysis.

In order to compare the relative size of the impact of four factors on air passenger and cargo traffic, choose standardized regression coefficients to reflect the strength of the impact of independent variables on the dependent variables. The larger the value, the higher the importance of the dependent variable is.

Multiple linear regression formulas of the first stage are shown as below:

$$
\begin{aligned}
& Y_{1}=0.247 X_{1}+0.249 X_{2}+0.247 X_{3}+0.246 X_{4} \\
& Y_{2}=0.249 X_{1}+0.251 X_{2}+0.249 X_{3}+0.247 X_{4}
\end{aligned}
$$

Multiple linear regression formulas of the second stage are shown as below:

$$
\begin{aligned}
& Y_{1}=0.266 X_{1}+0.270 X_{2}+0.266 X_{3}+0.219 X_{4} \\
& Y_{2}=0.248 X_{1}+0.252 X_{2}+0.248 X_{3}+0.204 X_{4}
\end{aligned}
$$

In four equations, the adjusted $\mathrm{R}$ square are $0.951,0.962,0.904,0.961$, illustrating that the fit is good in each equation; F-statistic in significant test of four equations are 155,204,66,23, and pass the test of significance with obvious results. $T$ statistic values and two-tailed significance probability also shows a significant degree of the variable.

As known in four equations, standardized regression coefficients of independent variables are positive. It shows that in Shanghai, these four factors, population urbanization, economy urbanization, land urbanization and social urbanization, work together to promote the development of aviation passenger and cargo industry. Economy urbanization has been the main driving force, with the greatest impact coefficients; second is population urbanization and land urbanization, sharing the same impact coefficients; Weakest is land urbanization. As can be seen from the trends, in the first stage, the impact of the four factors affecting almost the same; but in the second stage, population urbanization, economy urbanization and land urbanization share the same rising trend; but the impact of social urbanization undergoes reducing, with a growing gap.

Economy urbanization promotes origin demand for air transport. In terms of non-agricultural industries in Shanghai, raw materials and products have a lot of air logistics needs, and there are plenty of business aviation passenger demands. During 1995-2012, non-agricultural industries were developing rapidly, with a high speed and largest coefficient of impact on air transport industry. 
The impact of land urbanization is mainly reflected in two aspects, the impact of diverse transportation needs of highly concentrated population in built-up area which is embodied by population urbanization and the impact of comprehensive road network of the city on transportation accessibility between the airport and industrial or business area. The higher the level of land urbanization, the larger the coverage area of the comprehensive road network, the more convenient urban logistics and human interaction between the various regions and the airport, the higher accessibility of the city airport. During1995-2012, Shanghai had experienced the process of the formation of a comprehensive road network from main-line network to complete. So the impact of land urbanization presents the overall upward trend.

Population urbanization is also the basis for the development of the air transport industry, by the relative stability of demand of large-scale interaction on passenger flow, cargo flow and business flow between the city and the outside world to affect the air transport industry. Population urbanization not only provides relatively stable periodic flow, such as visiting relatives, travel flow and business flow, but also produces great freight demand in large batches and small quantities of express and parcels. In the urbanization construction, the vacancy of newly developed plots has been controlled in Shanghai. It guaranteed that after the completion of infrastructure, industries and population would converge rapidly. Therefore, the impact of population urbanization, land urbanization and economy urbanization can basically keep pace.

Social urbanization reflects the living standard of inhabitants who share health care, education and other public resources from government. The impact of social urbanization on air transport industry is reflected by the scale of demand for air travel by inhabitants under the existing conditions of life. The higher living standards go, the more air passenger traffic is. During 1995-2012, social urbanization lagged behind the other three aspects of urbanization, and then, the living standards of inhabitants grew with a lower speed. Therefore, compared with other three aspects, social urbanization has a smaller leading role in impacting on air transport industry.

\section{Conclusions}

During the structure-adjustment period of Shanghai's urbanization, the impact of population urbanization, economy urbanization, land urbanization and social urbanization on the air transport industry is basically the same; during the coordination-development period of Shanghai's urbanization, the impact of population urbanization, economy urbanization, land urbanization becomes the main driving force of the air transport industry. Therefore, when planning development of the air transport industry in major cities, in addition to emphasis on industrial and infrastructure stimulus, we should fix our attention on the impact of population urbanization.

Based on an actual problem, this paper draws the impact factors of urbanization on the development of the air transport industry in Shanghai, presenting important references for the development of the air transport, especially the plan of large-scale airport. But the mechanism of the impact of each urbanization subsystem on the air transport industry requires the in-depth study.

\section{References}

[1] G.F. Xuan, J.G. Xu and J. Zhao: Areal Research and Development, Vol. 24 (2005) No.3, p.47-51, in Chinese.

[2] D.D. Lu: Urban Planning Forum, Vol. 4 (2007) No.4, p. 47-52, in Chinese.

[3] X.J. Ou, F. Zhen, Y.D. Qin, L.Z. Zhu and H. Wu: Geographical Research, Vol. 27 (2008) No.5, p. 993-1002, in Chinese.

[4] Y.C. Cao, Y.R. Xi and W.W. Li: Inquiry into Economic Issues, Vol. 7 (2009) No.2, p. 49-54, in Chinese. 
[5] Debbage K G and DelK D: Journal of Air Transport Management, Vol. 7 (2001) No.3, p. 159167.

[6] Van den Berg L, Van K link H A and Pol P M J: Transport Reviews, Vol. 16 (1996) No.1, p.55-65.

[7] Guilherme L, Sascha A and Benjamin K: Journal of Air Transport Management, Vol. 15 (2009), p. 205-211.

[8]X.W. Liu, D.X. Zhang and B.M. Chen: Acta Geographica Sinica, Vol. 63 (2008) No.3, p. 301-310, in Chinese.

[9]Cox LD: Journal of Airport Management, Vol. 3 (2010) No.4, p. 49-55.

[10]Y.H. Chang and Y.W. Chang: Journal of Air Transport Management, Vol. 15 (2009) No.5, p. 264-265.

[11] M. Chen: Habitat International, Vol. 38 (2013) No.4, p.25-33. 